\title{
Achieving High Selectivity for Alkyne Hydrogenation at High Conversions with Compositionally Optimized PdAu Nanoparticle Catalysts in Raspberry Colloid-Templated $\mathrm{SiO}_{2}$
}

\author{
Mathilde Luneau ${ }^{1}$, Tanya Shirman ${ }^{2,3}$, Alexandre C. Foucher ${ }^{4}$, Kaining Duanmu ${ }^{5}$, David M.A. \\ Verbart $^{1,6}$, Philippe Sautet ${ }^{5,7}$, Eric A. Stach ${ }^{4}$, Joanna Aizenberg ${ }^{1,2,3}$, Robert J. Madix ${ }^{2}$ and \\ Cynthia M. Friend ${ }^{1,2, *}$ \\ ${ }^{1}$ Department of Chemistry and Chemical Biology, Harvard University, Cambridge, MA 02138, USA. \\ ${ }^{2}$ John A. Paulson School of Engineering and Applied Sciences, Harvard University, Cambridge, \\ MA 02138, USA. \\ ${ }^{3}$ Wyss Institute for Biologically Inspired Engineering, Harvard University, Cambridge, MA 02138 , \\ USA. \\ ${ }^{4}$ Department of Materials Science and Engineering, University of Pennsylvania, Philadelphia, PA \\ 19104, USA \\ ${ }^{5}$ Department of Chemical and Biomolecular Engineering, University of California, Los Angeles, \\ CA 90095, US \\ ${ }^{6}$ Inorganic Chemistry and Catalysis, Debye Institute for Nanomaterials Science, Utrecht \\ University, Universiteitsweg 99, 3584 CG Utrecht, The Netherlands \\ ${ }^{7}$ Department of Chemistry and Biochemistry, University of California, Los Angeles, CA 90095, US \\ *corresponding author: friend@harvard.edu
}

\section{S1: Materials and methods}

Styrene, acrylic acid, ammonium peroxodisulfate, gold (III) chloride hydrate ( $\mathrm{HAuCl}_{4}$, 99.995\%), palladium (II) nitrate hydrate $\left(\mathrm{Pd}\left(\mathrm{NO}_{3}\right)_{2}, 99.9 \%\right)$, sodium borohydride $\left(\mathrm{NaBH}_{4}, 99 \%\right)$, polyvinylpyrrolidone (PVP, MW 10K), sodium citrate, 2aminoethanethiol hydrochloride (AET, 98\%), N-Ethyl-N'-(3-(dimethylamino)propyl) carbodiimide hydrochloride (EDAC, $\geq 99.0 \%)$ and $2-(\mathrm{N}$-morpholino)ethanesulfonic acid (MES, $>99.5 \%$ ), tetraethyl orthosilicate (TEOS), nitric acid $\left(\mathrm{HNO}_{3}(\mathrm{aq}), 67-70 \% \mathrm{w} / \mathrm{w}\right)$, hydrochloric acid $(\mathrm{HCl}(\mathrm{aq}), 36.5-38.0 \% \mathrm{w} / \mathrm{w}$ and $0.1 \mathrm{M})$, hydrofluoric acid $(\mathrm{HF}, 50 \%)$, acetone and sand (white quartz, 50-70 mesh particle size) were purchased from Sigma-Aldrich. Ethanol was obtained from Koptec. ICP-MS calibration samples of $\mathrm{Au}$ (10 PPM) and Pd (10 PPM) were obtained from Inorganic Ventures. All the chemicals were used as received. Triply distilled deionized (DI) water (18 $\mathrm{M} \Omega$ ) was used in all experiments. All glassware and teflon-coated magnetic stir bars used in the metal nanoparticle synthesis were thoroughly cleaned in aqua regia $(3$ parts $\mathrm{HCl}, 1$ part $\mathrm{HNO}_{3}$ ) (Caution: highly corrosive) and rinsed in DI water.

Transmission Electron Microscopy (TEM) images were acquired using a JEOL 2100 microscope (Japan) with an operating voltage of $200 \mathrm{kV}$. The samples for TEM images were made by placing a drop of the MNPs solution on a TEM carbon-coated grid. High resolution images were taken using a Gatan Osiris digital camera. Scanning 
Transmission Electron Microscopy (STEM) images and Energy Dispersive X-ray spectroscopy (EDS) spectra were obtained on Aberration corrected TEM, JEOL Atomic-Resolution Analytical TEM - ARM200F at 200kV. Scanning Electron Microscopy (SEM) images were acquired using an FESEM Ultra55 (Zeiss) scanning electron microscope. For the post-reaction images: The STEM images were taken with a JEOL JEM-F200 transmission electron microscope, operating at a voltage of $200 \mathrm{kV}$. The pixel size of the EDS map is $0.93 \times 0.93 \mathrm{~nm}$ and obtained with DigitalMicrograph from Gatan. Gold and palladium ion concentrations were determined using an inductively coupled plasma atomic mass spectrometer (ICP-MS, Agilent Technologies 7700x). The nanoparticle samples were digested by the addition of aqua regia $\left(\mathrm{HNO}_{3}: \mathrm{HCl} 1: 3,0.7 \mathrm{~mL}\right)$. Gold and palladium calibration solutions were prepared just before analysis by dilution of a standard solutions of $\mathrm{HAuCl}_{4}$ (10 ppm in $2 \% \mathrm{HNO} 3$ ) and $\mathrm{Pd}(\mathrm{NO} 3) 2$ (10 ppm in $2 \% \mathrm{HNO}_{3}$ ) in $2 \% \mathrm{HNO}_{3}(\mathrm{aq})$, respectively.

$E x$-situ X-ray photoelectron spectroscopy (XPS) analyses were performed to identify surface elements and describe surface composition with a ThermoFisher K-alpha Xray photoelectron spectrometer equipped with an $\mathrm{Al}$ source and $180^{\circ}$ double focussing hemispherical analyzer and 128-channel detector.

\section{S2: Synthesis and characterization of metal nanoparticles (MNP)}

\section{S2.1 Synthesis of Au nanoparticles (NPs)}

Gold nanoparticles (AuNPs) were synthesized using modified published method. ${ }^{1}$ Typically, a solution of $\sim 5 \mathrm{~nm}$ AuNPs was prepared by adding of $10 \mathrm{mg}$ of $\mathrm{HAuCl}_{4}$ to $100 \mathrm{~mL}$ of $\mathrm{H}_{2} \mathrm{O}$ with vigorous stirring, followed one minute later by addition of $1 \mathrm{~mL}$ of $1 \%$ aqueous tri-sodium citrate. After an additional minute, $1 \mathrm{~mL}$ of $0.075 \% \mathrm{NaBH}_{4}$ in $1 \%$ tri-sodium citrate was added. The solution was stirred for $5 \mathrm{~min}$ and then stored at $4{ }^{\circ} \mathrm{C}$ until needed.

\section{S2.2 Pd NPs}

PVP-capped Pd NPs were synthesized by the $\mathrm{NaBH}_{4}$ reduction of $\mathrm{Pd}\left(\mathrm{NO}_{3}\right)_{2}$ according to published procedure with slight modification. Briefly, $4.3 \mathrm{~g}$ of PVP were added to 75 $\mathrm{mL}$ of $\mathrm{DI}$ water under stirring followed by addition of $13.64 \mathrm{mg}$ of $\mathrm{Pd}\left(\mathrm{NO}_{3}\right)_{2}$. The solution was capped in ice bath under $\mathrm{Ar}$ for 30 min under stirring, then $1.5 \mathrm{~mL}$ of $\mathrm{NaBH}_{4}$ aqueous solution $(0.5 \mathrm{M})$ was quickly added and the reaction flask was left in ice bath under $\mathrm{Ar}$ atmosphere for additional $10 \mathrm{~min}$. Then the reaction mixture was removed from the ice bath and left for aging for $48 \mathrm{~h}$ without stirring (covered, room temperature).

\section{S2.3 Au-Pd NPs}

As prepared Au NP solution was used to synthesize the AuxPdy bimetallic NPs using modified published procedure $(x, y=$ the molar percent of $\mathrm{Au}$ and $\mathrm{Pd}$, as determined from inductive coupled plasma mass spectrometry (ICP-MS)). ${ }^{2}$ Typically, to $40 \mathrm{~mL}$ of as synthesized AuNPs solution $5 \mathrm{~mL}$ of ascorbic acid aqueous solution $(0.1 \mathrm{M})$ was added under stirring at room temperature. The AuPd bimetallic NPs with various Au/Pd 
ratios were synthesized by addition of certain volumes of $\mathrm{Pd}\left(\mathrm{NO}_{3}\right)_{2}$ aqueous solution $(10 \mathrm{mM})$ : $60 \mu \mathrm{L}, 150 \mu \mathrm{L}$, and $400 \mu \mathrm{L}$ for the synthesis of $\mathrm{Pd}_{0.02} \mathrm{Au}_{0.98}, \mathrm{Pd}_{0.04} \mathrm{Au}_{0.96}$ and $\mathrm{Pd}_{0.09} \mathrm{Au}_{0.91}$, respectively. The reaction mixture was stirred for $12 \mathrm{~h}$ at room temperature and stored at $4{ }^{\circ} \mathrm{C}$.

S2.4 Synthesis and characterization of $\mathrm{Pd}_{\mathrm{x}} \mathrm{Au}_{1-\mathrm{x}}(\mathrm{x}=0.02,0.04$, and 0.09$)$ supported on raspberry colloid templated (RCT)-SiO . $_{2}$

A templating approach previously described was used to synthesize the final catalytic materials. 3,4

The schematic depiction of the synthetic approach is shown on Figure S1.
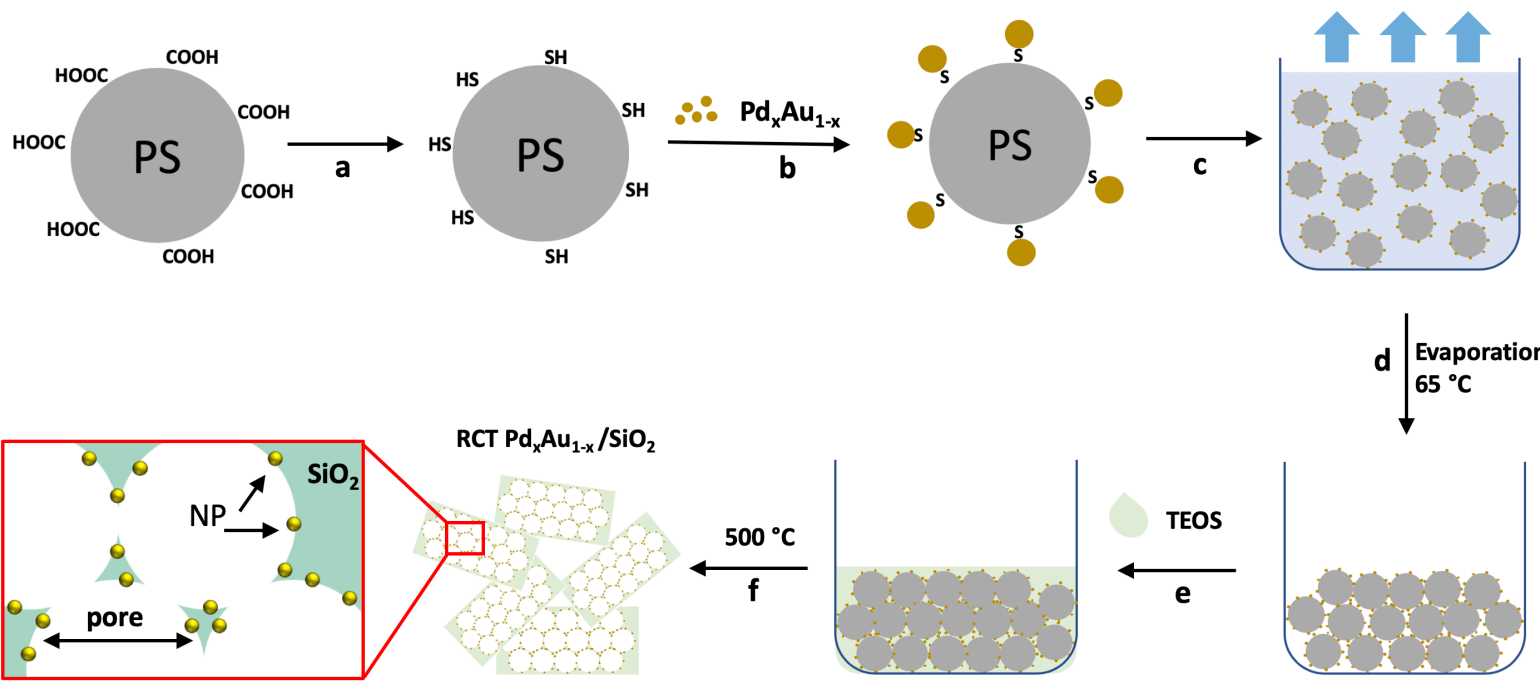

Figure S1. The schematic description of the synthetic approach for the fabrication of $\mathrm{Pd}_{x} \mathrm{Au}_{1-\mathrm{x}} \mathrm{NPs}$ supported on raspberry colloid templated (RCT)-SiO${ }_{2}$.

\section{S2.4.1 Synthesis of composite colloids (PS@Pdx $\left.A u_{1-x}\right)$}

Briefly, carboxylic acid-functionalized polystyrene colloids (PS-COOH) with diameter of $\sim 380 \mathrm{~nm}$ were synthesized by surfactant free emulsion polymerization, using acrylic acid as co-monomer and ammonium peroxodisulfate (APS) as an initiator following a recipe from the literature. ${ }^{5}$ Control over the diameter of the colloids can be achieved by altering the concentrations of styrene monomer and APS initiator.

The modification of PS-COOH with thiol was performed according to modified previously published methods (Fig. S1, step a) ${ }^{6}$ Typically, PS-COOH colloids $(10 \mathrm{ml}$ of $1 \%$ by weight) were dispersed in $0.5 \mathrm{ml}$ of MES buffer aqueous solution $(500 \mathrm{mM})$, then $4.4 \mathrm{ml}$ of EDAC was added (52 mM) while stirring. After $30 \mathrm{~min}$, AET (25 mg in $0.5 \mathrm{ml}$ of water) was added. The reaction mixture was stirred for $3 \mathrm{~h}$ followed by washing with water (centrifugation $\times 3$ at $9500 \mathrm{rpm}$ ).

Composite colloids (PS@PdxA $u_{1-x}$ ) were synthesized by adding specific amounts of $\mathrm{Pd}_{\mathrm{x}} \mathrm{Au}_{1-\mathrm{x}}$ nanoparticles to the colloidal dispersion of thiol-modified polystyrene colloids (Fig. S1, step b). The dispersion was stirred for $2 \mathrm{~h}$, washed three times using 
centrifugation (9500rpm $\times 7 \mathrm{~min}$ ), and re-dispersed in water to give $\sim 5 \%$ colloidal dispersion and stored at $4{ }^{\circ} \mathrm{C}$.

\section{S2.4.2 Synthesis of $\mathrm{RCT} \mathrm{Pd}_{x} \mathrm{Au}_{1-\mathrm{x}} / \mathrm{SiO}_{2}$ catalyst}

The backfilling method was used to form $\mathrm{RCT} \mathrm{SiO}_{2}$-based structures. The colloidal dispersion of $\sim 4 \mathrm{ml}(\sim 5 \mathrm{w} \%)$ of composite colloids ( $\left.P S @ P d_{x} A u_{1-x}\right)$ was introduced into a $40 \mathrm{ml}$ falcon tube and placed in the oven at $65^{\circ} \mathrm{C}$ to evaporate water and form the colloidal assembly (Fig. S1, steps $\mathrm{c}$ and d). A few drops of prehydrolized TEOS solution was placed on the assembled structure leading to interstitial space filling between the PS spheres by capillary forces (Fig. S1, step e). Prehydrolized TEOS solution was prepared by mixing of $0.1 \mathrm{M}$ of $\mathrm{HCl}$, ethanol, and TEOS in 1:1:1 ratio by weight, and stirred at room temperature for at least $1 \mathrm{~h}$ prior to use. The backfilled samples were dried at $65^{\circ} \mathrm{C}$ for $\sim 1 \mathrm{~h}$ and then transferred into glass vials. The backfilled samples were dried and finally calcined at $500^{\circ} \mathrm{C}$ in air for two hours to remove polymer colloids and organic volatiles, and solidifies the matrix into $\mathrm{SiO}_{2}$ (Fig. S1, step f).

Various NPs, raspberry colloids and catalysts samples were characterized using TEM and SEM (Figures S2 and S3). NPs size, composition and total metal loading in catalytic powders are summarized in Table S1.
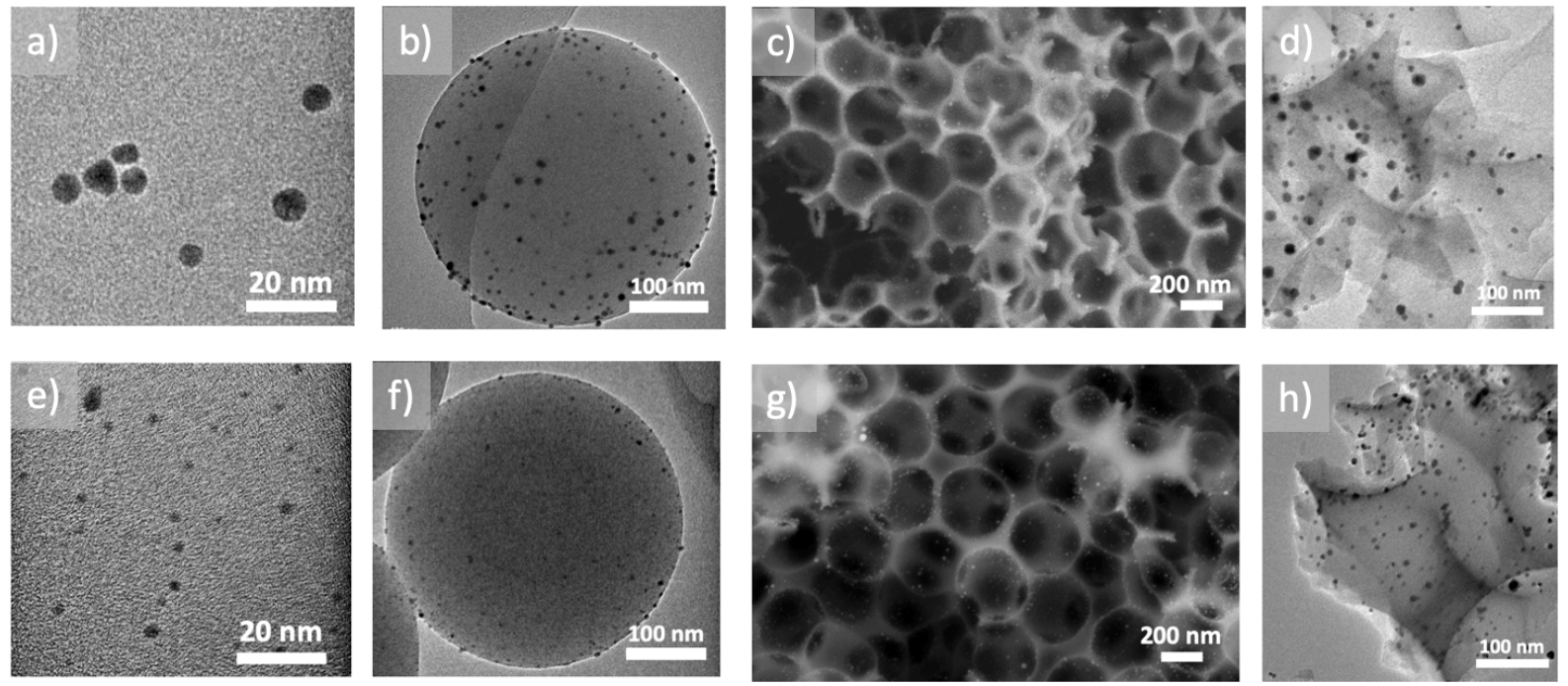

Figure S2: Representative TEM images of as synthesized a) Au NPs and e) Pd NPs; raspberry templating colloids b) PS@AuNPs and f)PS@PdNPs. Representative SEM and TEM images of c-d) Au RCT-SiO ${ }_{2}$ and g-h) Pd RCT-SiO 2 . 

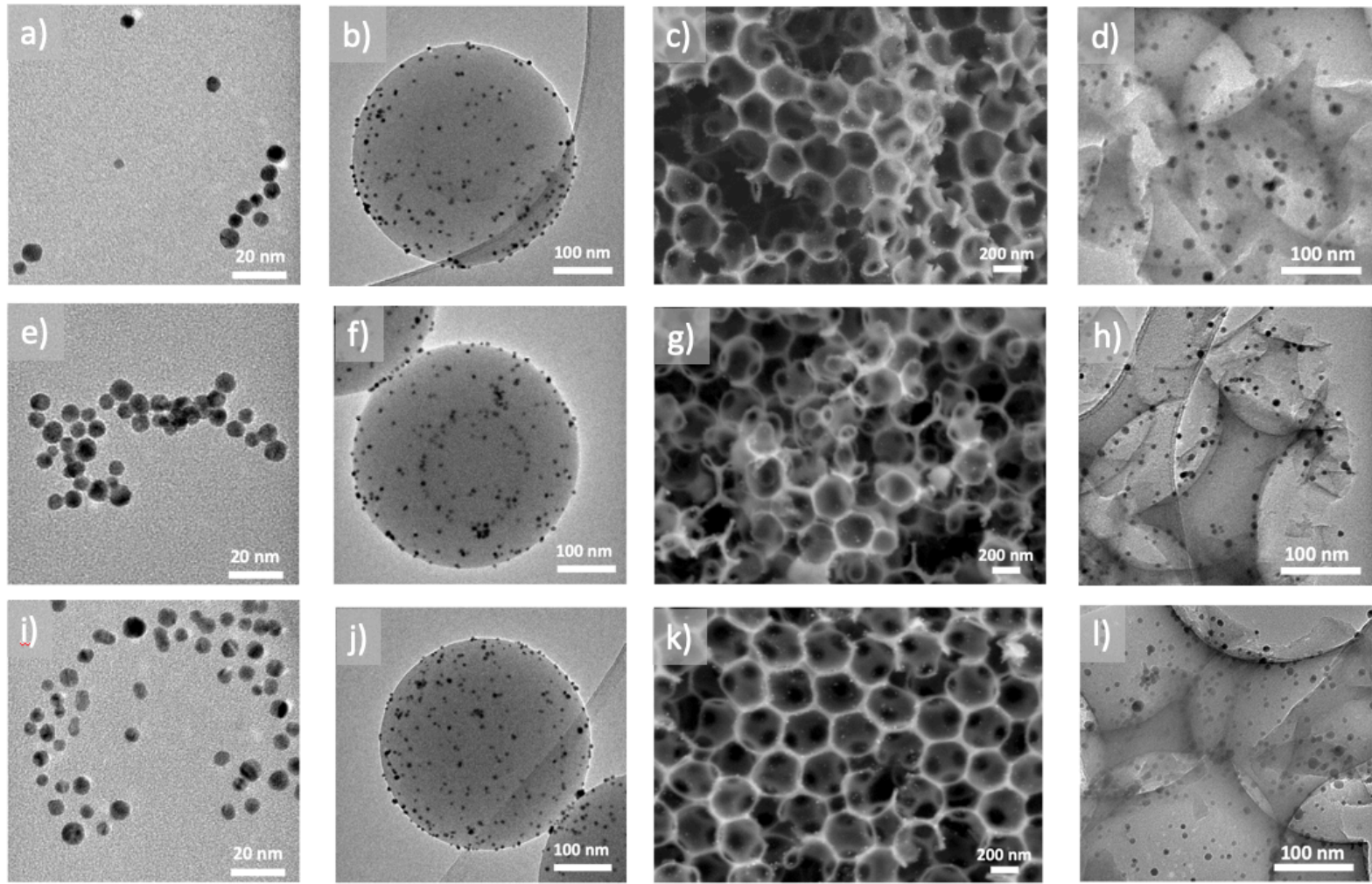

Figure S3: Representative TEM images of as synthesized $\mathrm{Pd}_{\mathrm{x}} \mathrm{Au}_{1-\mathrm{x}} \mathrm{NPs}$ : a) $\mathrm{Pd}_{0.02} \mathrm{Au}_{0.98}$ e) $\mathrm{Pd}_{0.04} \mathrm{Au}_{0.96}$ and i) $\mathrm{Pd}_{0.09} \mathrm{Au}_{0.91}$. Representative TEM images of raspberry templating colloids modified with b) $\mathrm{Pd}_{0.02} \mathrm{Au}_{0.98}$, f) $\mathrm{Pd}_{0.04} \mathrm{Au}_{0.96}$ and j) $P \mathrm{~d}_{0.09} A u_{0.91}$. SEM and TEM images of $\mathrm{Pd}_{x} \mathrm{Au}_{1-\mathrm{x}} \mathrm{RCT}-\mathrm{SiO}_{2}$ with c-d) $\left.\mathrm{Pd}_{0.02} \mathrm{Au}_{0.98}, \mathrm{~g}-\mathrm{h}\right) \mathrm{Pd}_{0.04} \mathrm{Au}_{0.96}$ and k-l) $\mathrm{Pd}_{0.09} \mathrm{Au}_{0.91}$.

\section{S3: Catalytic tests}

The conversion of 1-hexyne was calculated considering the products and reactants in the gas phase by:

$$
\frac{\mathrm{A}_{1-\mathrm{ENE}} / \sigma_{1-\mathrm{ENE}}+{ }^{\mathrm{A}_{2-\mathrm{ENE}}} / \sigma_{2-\mathrm{ENE}}+{ }_{3-\mathrm{ENE}} / \sigma_{3-\mathrm{ENE}}+{ }^{\mathrm{A}_{\mathrm{ANE}}} / \sigma_{\mathrm{ANE}}}{\mathrm{A}_{1-\mathrm{YNE}} / \sigma_{1-\mathrm{YNE}}+{ }^{\mathrm{A}_{1-\mathrm{ENE}}} / \sigma_{1-\mathrm{ENE}}+{ }^{\mathrm{A}_{2-\mathrm{ENE}}} / \sigma_{2-\mathrm{ENE}}+{ }_{3-\mathrm{ENE}} / \sigma_{3-\mathrm{ENE}}+{ }^{\mathrm{A}_{\mathrm{ANE}}} / \sigma_{\mathrm{ANE}}}
$$

where $A_{1-Y N E}, A_{1-E N E}, A_{2-E N E}, A_{3-E N E}$ and $A_{\text {ANE }}$ are the peaks areas of 1-hexyne, 1hexene, 2-hexene, 3-hexene and hexane respectively. $\sigma$ corresponds to the ionization cross sections ${ }^{7}$.

The selectivity towards 1-hexene was calculated by :

$$
\frac{\mathrm{A}_{1-\mathrm{ENE}} / \sigma_{1-\mathrm{ENE}}}{\mathrm{A}_{1-\mathrm{ENE}} / \sigma_{1-\mathrm{ENE}}+\mathrm{A}_{2-\mathrm{ENE}} / \sigma_{2-\mathrm{ENE}}+\mathrm{A}_{3-\mathrm{ENE}} / \sigma_{3-\mathrm{ENE}}+{ }^{\mathrm{ANE}} / \sigma_{\mathrm{ANE}}}
$$



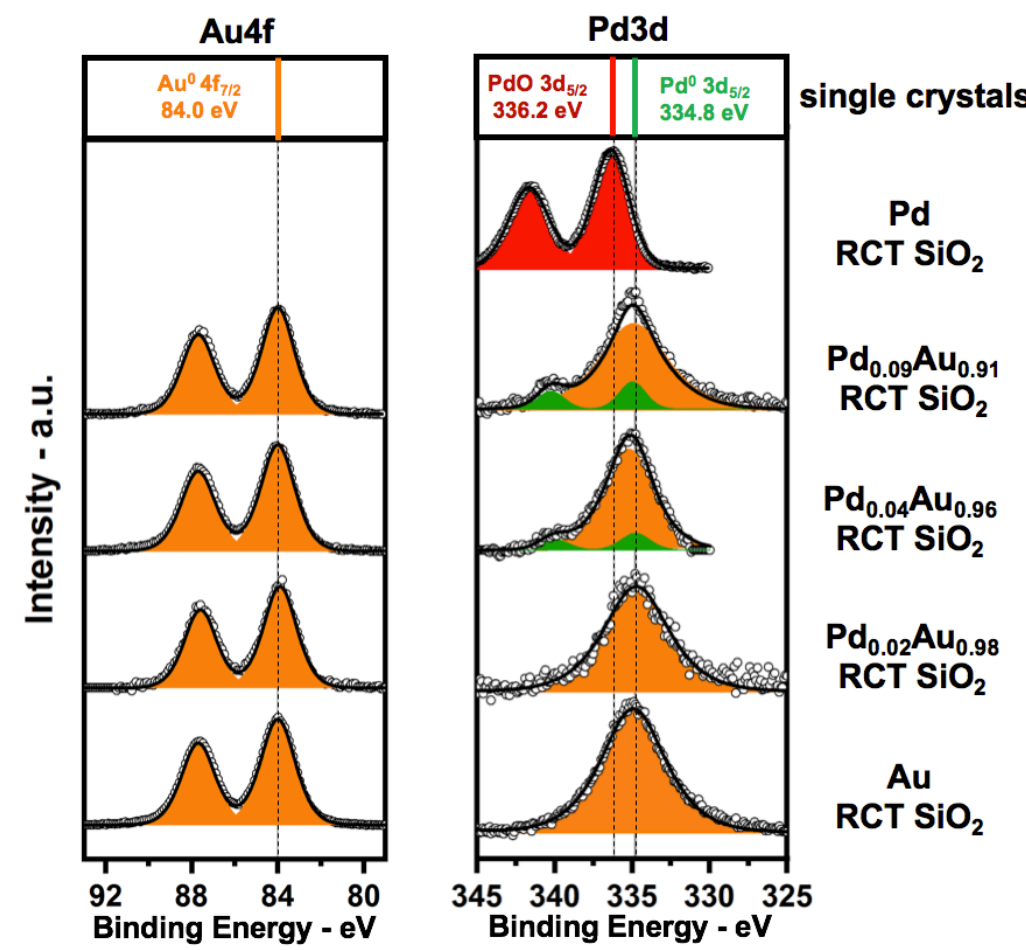

Figure S4: Ex-situ XPS spectra of $\mathrm{Au} 4 \mathrm{f}$ and $\mathrm{Pd} 3 \mathrm{~d}$ regions of $\mathrm{Pd}, \mathrm{Pd}_{x} \mathrm{Au}_{1-\mathrm{x}}$ and $\mathrm{Au} \mathrm{RCT}-\mathrm{SiO}_{2}$ after calcination in air at $500^{\circ} \mathrm{C}$ for 2 hours. The $\mathrm{Pd} 3 \mathrm{~d}$ and $A u 4 \mathrm{~d}_{5 / 2}$ regions overlaps.
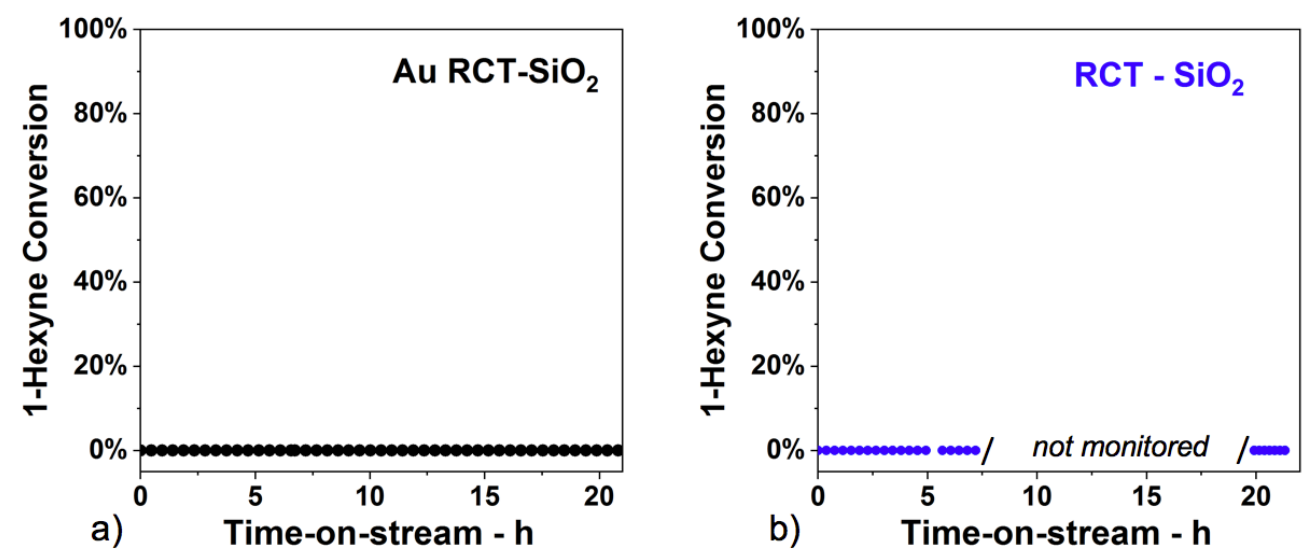

Figure S5: a) Au RCT-SiO ${ }_{2}$ and b) RCT-SiO ${ }_{2}$ without metal NPs are not active at $90^{\circ} \mathrm{C}-$ The reaction over pure $\mathrm{RCT} \mathrm{SiO}_{2}$ was not monitored between 7.5 and $20 \mathrm{~h}$ of reaction - Reaction conditions: 1\% 1-hexyne, $20 \% \mathrm{H}_{2}$, He balance; $\mathrm{m}_{\text {Au RCT-SiO2 }}=20 \mathrm{mg} ; \mathrm{m}_{\mathrm{RCT} \text {-SiO2 }}=23 \mathrm{mg}$; Total flow rate $=50 \mathrm{~mL} \mathrm{~min}{ }^{-1} ; \mathrm{GHSV}=3,800 \mathrm{~h}^{-1}$ 

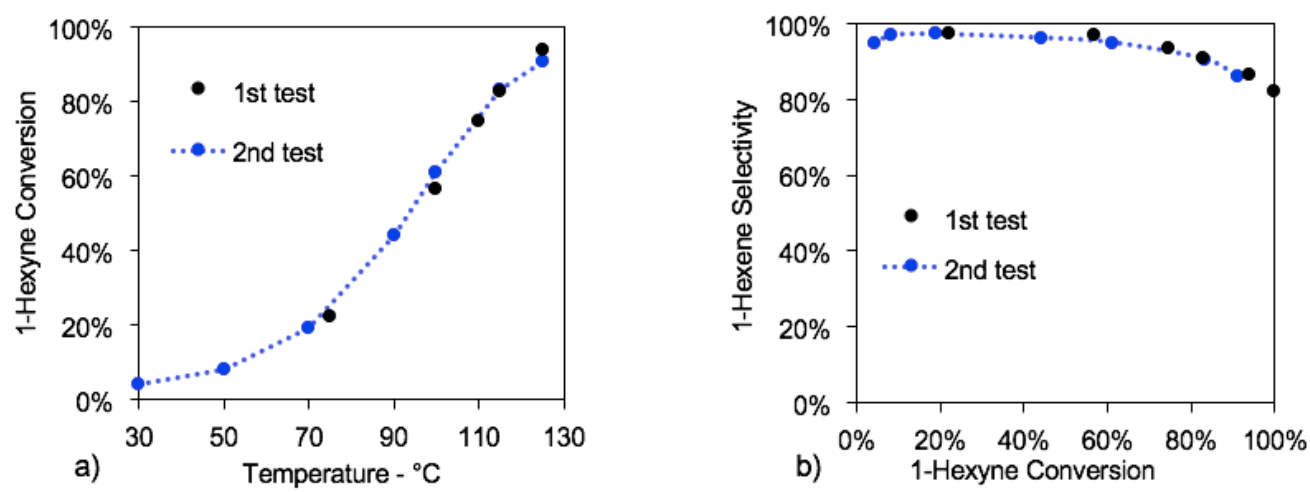

Figure S6: a) 1-Hexyne conversion as a function of temperature and b) 1-Hexene selectivity as a function of 1-Hexyne conversion over two different batches with the same composition $\mathrm{Pd}_{0.04} \mathrm{Au}_{0.96} \mathrm{RCT}_{-} \mathrm{SiO}_{2}$; Reaction conditions: 1\% 1-Hexyne, $20 \% \mathrm{H}_{2}$, He balance, Total flow rate $=50 \mathrm{~mL} \mathrm{~min}^{-1}, \mathrm{GHSV}=3,800 \mathrm{~h}^{-1}$

Table S1: Evaluation of internal and external mass transfer limitations

\begin{tabular}{c|c|c}
\hline Limitation & Number & Calculations \\
\hline Internal mass transfer & ${\text { Weisz } \text { Prater }^{8}}$ & $0.004<0.08$ \\
External mass transfer & Carberry $^{9}$ & $0.0007<0.05$ \\
\hline
\end{tabular}
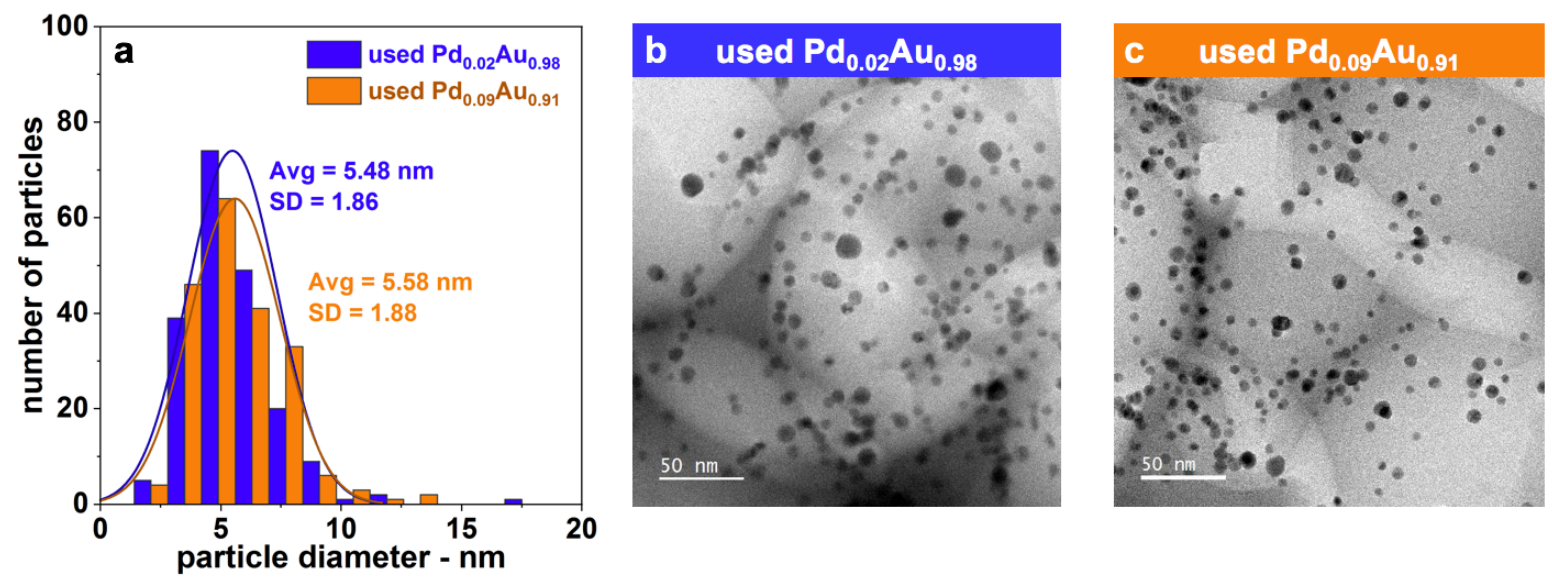

Figure S7: Post-reaction TEM analysis of the particle size distribution of used $\mathrm{Pd}_{0.02} \mathrm{Au}_{0.98}$ and $\mathrm{Pd}_{0.09} \mathrm{Au}_{0.91} \mathrm{RCT}-\mathrm{SiO}_{2}$ show that the catalysts are resistant to sintering. 


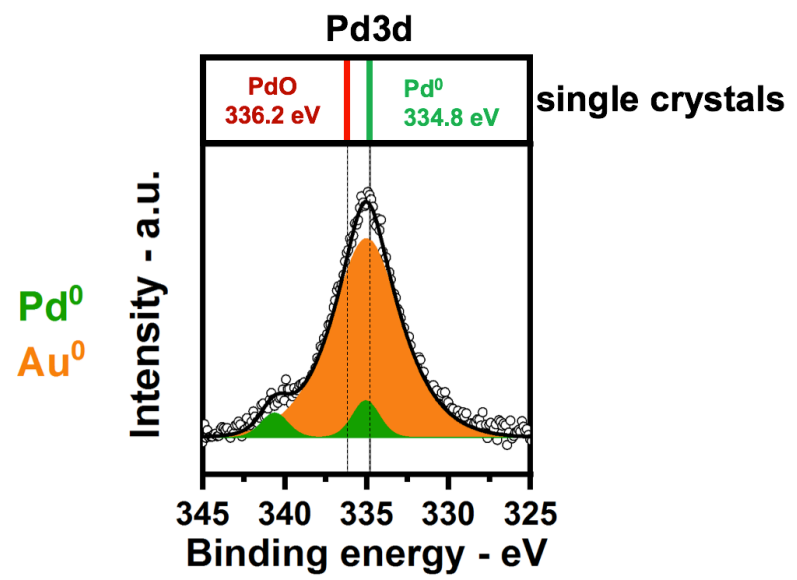

Figure S8: Pd is still present at the surface of $\mathrm{Pd}_{0.04} \mathrm{Au}_{0.96} \mathrm{RCT}^{-\mathrm{SiO}_{2}}$ as shown by ex-situ XPS spectra of the Pd3d region of the used catalyst.
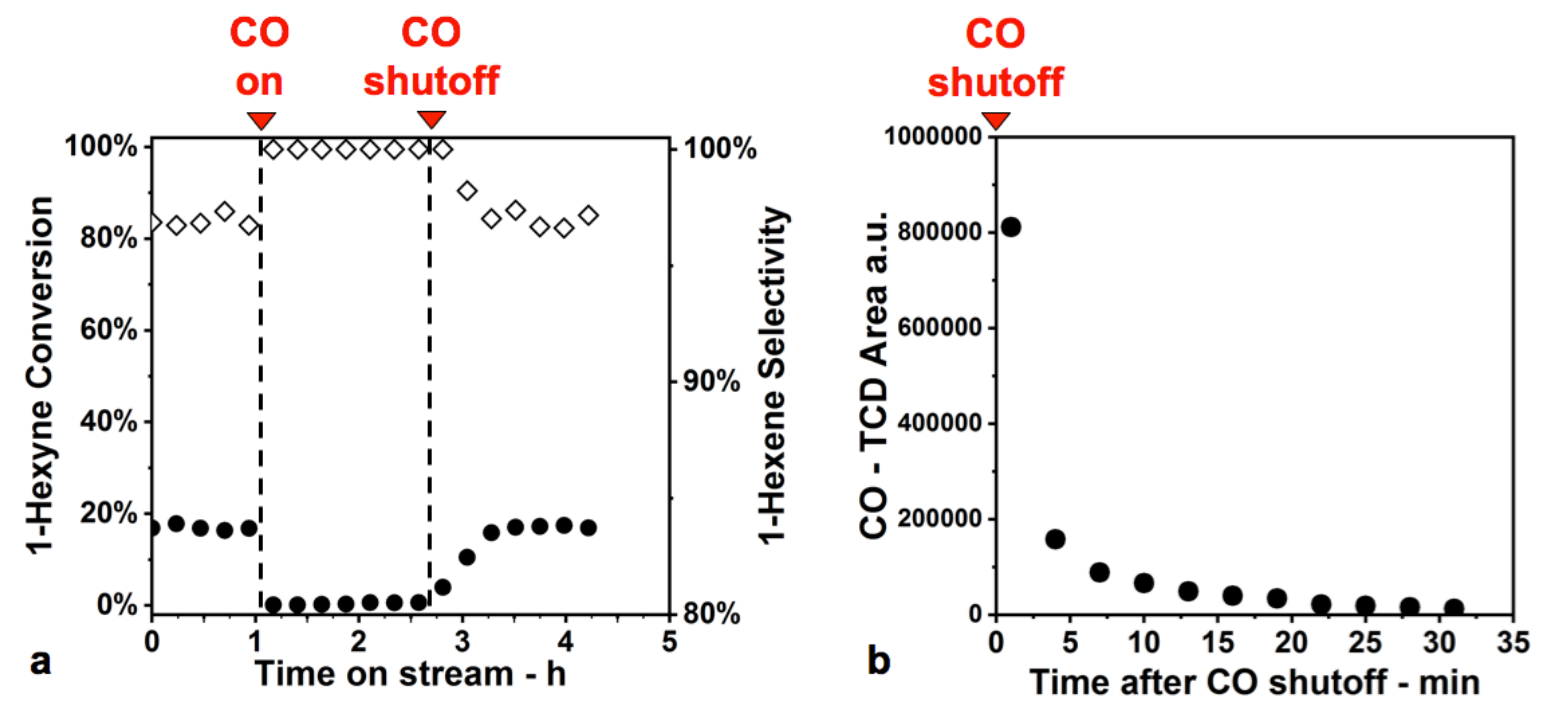

Figure S9: a) 1-Hexyne conversion as a function of time-on-stream with $\mathrm{CO}$ introduced after 1 hour then returned to standard conditions without $\mathrm{CO}$ after $\sim 2.5$ hours on stream b) it takes 20 to $30 \mathrm{~min}$ for $\mathrm{CO}$ to be completely purged out of the reactor lines after shutoff at $75^{\circ} \mathrm{C}$ which corresponds to the time it takes for the activity of hexyne hydrogenation to be totally recovered ; Reaction conditions: $1 \% 1-\mathrm{Hexyne}, 20 \% \mathrm{H}_{2}$, He balance, $0-1 \% \mathrm{CO}$, Total flow rate $=50 \mathrm{~mL} \mathrm{~min}^{-1}, \mathrm{~T}=75^{\circ} \mathrm{C}, \mathrm{GHSV}=3,800 \mathrm{~h}^{-1}$ 


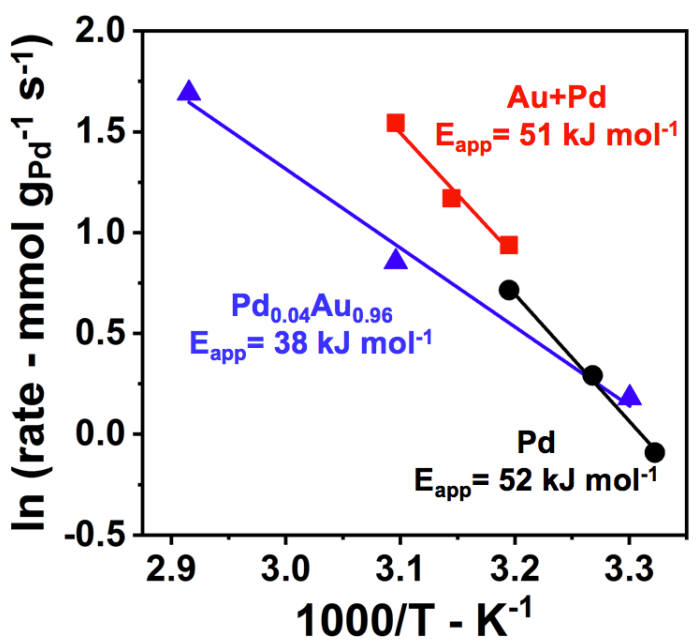

Figure S10: The apparent activation energies for $\mathrm{Pd}, \mathrm{Pd}_{0.04} \mathrm{Au}_{0.96} \mathrm{RCT}-\mathrm{SiO}_{2}$ and a physical mixture of monometallic $\mathrm{Pd}$ and $\mathrm{Au} \mathrm{RCT}-\mathrm{SiO}_{2}$ with the same $\mathrm{Pd}$ :Au composition (4 at\% $\mathrm{Pd}$ ); Reaction conditions: $1 \%$ 1-Hexyne, $20 \% \mathrm{H}_{2}$, He balance, Total flow rate $=50 \mathrm{~mL} \mathrm{~min}^{-1}$, GHSV $=3,800 \mathrm{~h}^{-1}$

Table S2: Comparison of $\mathrm{Pd}$ and $\mathrm{Pd}_{0.04} \mathrm{Au}_{0.96} \mathrm{RCT}-\mathrm{SiO}_{2}$ during hydrogenation of 1-hexene at $50^{\circ} \mathrm{C}$. Reaction conditions: $1-\mathrm{Hexene}, 20 \% \mathrm{H}_{2}$, He balance, Total flow rate $=50 \mathrm{~mL} \mathrm{~min}^{-1}, \mathrm{~T}=$ $50^{\circ} \mathrm{C}, \mathrm{GHSV}=3,800 \mathrm{~h}^{-1}$

\begin{tabular}{c|c|c|c|c}
\hline Catalyst & $\begin{array}{c}\text { Temperature } \\
{ }^{\circ} \mathrm{C}\end{array}$ & $\begin{array}{c}\text { Hexene } \\
\text { Conversion }\end{array}$ & $\begin{array}{c}2,3 \text { Hexenes } \\
\text { Selectivity }\end{array}$ & $\begin{array}{c}\text { Hexane } \\
\text { Selectivity }\end{array}$ \\
\hline $\mathrm{Pd} \mathrm{RCT}-\mathrm{SiO}_{2}$ & 50 & $39.7 \%$ & $67.0 \%$ & $33.0 \%$ \\
$\mathrm{Pd}_{0.04} \mathrm{Au}_{0.96} \mathrm{RCT}-\mathrm{SiO}_{2}$ & 50 & $38.1 \%$ & $85.5 \%$ & $14.6 \%$ \\
\hline
\end{tabular}

\section{References:}

(1) Grabar, K. C.; Allison, K. J.; Baker, B. E.; Bright, R. M.; Brown, K. R.; Freeman, R. G.; Fox, A. P.; Keating, C. D.; Musick, M. D.; Natan, M. J. Two-Dimensional Arrays of Colloidal Gold Particles: A Flexible Approach to Macroscopic Metal Surfaces. Langmuir 1996, 12, 2353-2361.

(2) Ding, Y.; Fan, F.; Tian, Z.; Wang, Z. L. Atomic Structure of Au-Pd Bimetallic Alloyed Nanoparticles. J. Am. Chem. Soc. 2010, 132, 12480-12486.

(3) Shirman, T.; Lattimer, J.; Luneau, M.; Shirman, E.; Reece, C.; Aizenberg, M.; Madix, R.; Aizenberg, J.; Friend, C. M. New Architectures for Designed Catalysts: Selective Oxidation Using AgAu Nanoparticles on Colloid-Templated Silica. Chem. - A Eur. J. 2017, 24, 1833-1837.

(4) Shirman, E.; Shirman, T.; Shneidman, A. V; Grinthal, A.; Phillips, K. R.; Whelan, H.; Bulger, E.; Abramovitch, M.; Patil, J.; Nevarez, R.; et al. Modular Design of Advanced Catalytic Materials Using Hybrid Organic - Inorganic Raspberry Particles. Adv. Funct. Mater. 2017, 1704559, 1-20.

(5) Vogel, N.; Viguerie, L. De; Jonas, U.; Weiss, C. K.; Landfester, K. Wafer-Scale Fabrication of Ordered Binary Colloidal Monolayers with Adjustable Stoichiometries. Adv. Funct. Mater. 2011, 21, 3064-3073. 
(6) Shi, W.; Sahoo, Y.; Swihart, M. T.; Prasad, P. N. Gold Nanoshells on Polystyrene Cores for Control of Surface Plasmon Resonance. Langmuir 2005, No. 2, 1610-1617.

(7) Harrison, A. G.; Jones, E. G.; Gupta, S. K.; Nagy, G. P. Total Cross Sections for Ionization by Electron Impact. Can. J. Chem. 1968, 44 (1966).

(8) Froment, G. F.; Bischoff, K. B. Chemical Reactor Analysis and Design; Wiley: New York, 1990.

(9) Carberry, J. J. Physico-Chemical Aspects of Mass and Heat Transfer in Heterogeneous Catalysis. In Catalysis Science and Technology, Anderson, J. R., Boudart, M., Eds.; Springer: Berlin, 1987; Vol. 8, pp 131-172. 